\section{THE IMPACT URBANIZATION HAS ON LAW ENFORCEMENT STRESS DURING TRAUMATIC CALLS FOR SERVICE}

Rebecca Molsberry, Alaina Beauchamp, Amanda Smith, Katelyn Jetelina . University of Texas Health Science Center, School of Public Health

\subsection{6/injuryprev-2020-savir.137}

Statement of Purpose To evaluate how place (i.e. urban and rural) impacts stressors for law enforcement officers (LEOs) during traumatic calls for service.

Methods/Approach LEOs were recruited for six focus groups across one urban and one rural police department from April to November 2019. A semi-structured format was used to gain insight into how officers respond to consecutive highstress calls for service, including the mechanistic effects of decompression techniques and mental health care utilization. Transcripts were thematically analyzed in an iterative deductive and inductive coding scheme to identify anticipated and emergent findings.

Results A total of 22 LEOs participated, with mean ages of urban and rural officers of 37.9 and 40.8, respectively. Several similarities between urban and rural LEOs emerged related to consecutive stress: 1) Lack of officers to meet high volume of calls; 2) Stringent and fluid management; 3) Environmental stressors leading to a cyclical nature of calls. Rural officers reported unique stress due to: 1) Distance to calls 2) Lack of partners; 3) Lengthy backup response times; 4) Limited or no access to mental health care. Urban officers uniquely reported: 1) Large volume of civilian-police interactions; and 2) Negative perceptions from media and the public.

Conclusions While all LEOs experience consecutive stress, the nature of the stress differs by rural vs. urban employment location. Additional research and interventions for these two, unique populations are needed to combat consecutive stress and reduce LEO injuries.

Significance and Contributions to Injury and Violence Prevention Science Consecutive and continuous exposure to highstress calls may influence police officers' immediate risk for morbidity and mortality and inhibit their decision-making ability. Past literature has only focused on single police departments making it difficult to evaluate how context, like urban and rural environments, influence LEO stress.

\section{A MIXED-METHODS STUDY OF SCHOOL DAY ACTIVITIES, TRIGGERS FOR VIOLENT ASSAULT, AND LOCATION-SPECIFIC OPPORTUNITIES TO CONFER STUDENT SAFETY}

${ }^{1}$ Douglas Wiebe, ${ }^{1}$ Catherine McDonald, ${ }^{1}$ Therese Richmond, ${ }^{3}$ Joel Fein, ${ }^{4}$ Alison Culyba, ${ }^{2}$ Charles Branas, ${ }^{1}$ Theresa Soya. ${ }^{1}$ University of Pennsylvania; ${ }^{2}$ Columbia University; ${ }^{3}$ The Children's Hospital of Philadelphia; ${ }^{4}$ University of Pittsburgh

\subsection{6/injuryprev-2020-savir.138}

Purpose School violence, frequently resulting in serious injury, is a major public health concern, and can make students afraid to go school. Few studies investigate the myriad factors that contribute to school violence. We are conducting a mixed-methods study of school assaults, including violence that happen on the way to or from school.

Approach In an urban environment, this NIJ-funded study of 12-18 year-olds involves using a map-based interview of the path of their activities up to the time of assault, with casecrossover analyses to identify situation-specific risk factors. Recruitment sites include a Level I trauma center, health clinics, and community centers.

Results With a goal of 200, 45 participants have been enrolledto date: $85 \%$ African American, 4\% Hispanic. Injuries sustained were blunt trauma (42\%), concussion (23\%), and fracture $(4 \%) .50 \%$ of the incidents were described as random violence, $35 \%$ as non-gang fight, and $8 \%$ as gang fight. $38 \%$ occurred inside school, $27 \%$ on school grounds, and $4 \%$ off site. None had been carrying a weapon at the time of the injury. Only $18 \%$ reported they knew how to acquire a gun, and $43 \%$ reported they would tell a teacher if a student had a gun at school whereas $57 \%$ reported they would not do so. Importantly, $65 \%$ of incidents were reported to police and of those, $80 \%$ of participants felt the police were helpful. However $50 \%$ of respondents felt the conflict was not resolved. $60 \%$ had a teacher highly invested in them and 65\% reported a teacher expects them to attend college. Thematic results thus far suggest students were vulnerable at moments when guardianship was absent, which varied from location to location during the school day.

Conclusions and Significance Understanding the context of the timing and nature of school-based assaults can inform opportunities for place-based interventions. 